\title{
Heterocyst Development in Anabaena cylindrica: The Necessity for Light as an Initial Trigger and Sequential Stages of Commitment
}

\author{
By S. BRADLEY AND N. G. CARR \\ Department of Biochemistry, University of Liverpool, P.O. Box I47, \\ Liverpool L69 $3 B X$
}

(Received 2 March 1977)

\begin{abstract}
An initial light-dependent stage in heterocyst formation in Anabaena cylindrica was observed. The length of the period of illumination, between 3 and $9 \mathrm{~h}$, determined the frequency $o$ mature heterocyst production. Sequential stages of commitment to both proheterocyst and heterocyst formation were shown by manipulation of the light period, ammonia, drugs and analogues. The modulated response of potential heterocyst-forming cells in a filament, requiring sustained periods of light and lack of nitrogen source, is described.
\end{abstract}

\section{INTRODUCTION}

Many species of filamentous blue-green algae (cyanobacteria) develop heterocysts. These are morphologically specialized cells which are thought to be the major sites of nitrogen fixation. Their formation offers an experimentally attractive example of cellular differentiation and interaction, and of pattern imposition (see Carr \& Bradley, I973; Wilcox, Mitchison \& Smith, 1975; Wolk, 1975). They are readily distinguishable from the vegetative cells of Anabaena cylindrica filaments. The time sequence of heterocyst formation in $A$. cylindrica and the lack of relationship between imposition of heterocyst pattern and functional nitrogen fixation has been examined in cultures (Bradley \& Carr, 1976) and in single filaments (Wilcox, Mitchison \& Smith, 1973). Heterocysts are produced when a culture of A. cylindrica is deprived of fixed nitrogen (Fogg, 1949) and the manipulation of ammonia in the medium has been the major technique in laboratory experiments on heterocyst development.

Singh \& Kumar (1971) have described the development of heterocysts in Anabaena doliolum in the dark after a period of illumination, but on the basis of 3-(3,4-dichlorophenyl)I, I-dimethylurea (DCMU) inhibition studies they concluded that the control of heterocyst development was photosynthetic. This paper examines the role of light on heterocyst formation after $A$. cylindrica has been initiated into morphogenesis by removal of ammonia and suggests that there is an obligatory light-dependent stage followed by light-independent processes. We use the two stages of development, proheterocysts and mature heterocysts, as defined by Bradley \& Carr (1976). These definitions are based on arbitrary criteria that are recognizable in the light microscope. They are at present the only markers of development that can be observed readily.

\section{METHODS}

Organisms and growth. Anabaena cylindrica $1403 / 2$ a was obtained from the Culture Collection of Algae and Protozoa, The Botany School, Cambridge, and maintained as described by Bradley \& Carr (1976). The development of heterocysts was accomplished in batch cultures (I 1) of $\boldsymbol{A}$. cylindrica grown at $30^{\circ} \mathrm{C}$ in Allen \& Arnon's (1955) medium, supplemented with ammonium chloride ( $2 \mathrm{~mm}$ ), using a pilot fermenter illumi- 
nated by a $60 \mathrm{~W}$ tungsten bulb at a distance of $10 \mathrm{~cm}$; the mean generation time under these conditions was $18 \mathrm{~h}$. The cells were harvested by centrifugation in sterile I 1 polypropylene pots at $2500 \mathrm{~g}$ for $7 \mathrm{~min}$, and washed twice with sterile Allen \& Arnon's medium. The temperature was maintained at $\circ$ to $4{ }^{\circ} \mathrm{C}$. The cells were resuspended in sterile minimal medium (without ammonium chloride), introduced into a 1 vessel and illuminated with a $100 \mathrm{~W}$ tungsten bulb at a distance of $10 \mathrm{~cm}$. The algae were maintained in suspension by magnetic stirring and gassing with air/carbon dioxide $(95: 5, \mathrm{v} / \mathrm{v})$. Samples of algae were removed at intervals and incubated in the dark (or in the presence of inhibitors) with the same gas phase. Parallel experiments were performed in which the main algal suspension was illuminated for various periods before incubation in the dark for the rest of the experiment. Under these conditions growth (measured as $E_{650}$ ) ceased soon after transfer to ammonia-free medium, and did not recommence until mature heterocysts (with functional nitrogenase) had been formed. Cell division is difficult to assess in a filamentous organism growing in liquid culture, but there was no detectable alteration in vegetative cell size during heterocyst development. The experimental procedure did not affect culture growth, compared with that of an ammonia-free, continuous light control, over the developmental period. The term total heterocyst population denotes the sum of proheterocysts and mature heterocysts.

To investigate the effects of added inhibitors, the following were tested at the concentrations indicated: rifampicin ( $2 \mu \mathrm{g} \mathrm{ml}^{-1}$ ), 5 -fluorouracil, 5 -bromouracil and 5-bromodeoxyuridine (each $10 \mu \mathrm{g} \mathrm{ml}^{-1}$ ), proflavin (I $\mu \mathrm{g} \mathrm{ml}^{-1}$ ), carbonyl cyanide $p$-trifluoromethoxyphenylhydrazone (I $\mu \mathrm{g} \mathrm{ml}^{-1}$ ) and ammonium chloride (to a final concentration of $2 \mathrm{~mm}$ ).

Carbon dioxide fixation. Samples of algae from a differentiating culture were harvested and resuspended, by homogenization, in sterile minimal medium. Portions $(20 \mathrm{ml})$ of this suspension were incubated in boiling tubes, fitted with a gassing tube and a sampling tube, for $15 \mathrm{~min}$ in the light; during this time air was bubbled through the culture to keep the algae in suspension. Sodium $\left[{ }^{14} \mathrm{C}\right]$ bicarbonate $(20 \mu \mathrm{Ci})$ was added and incubation was continued with illumination by a $100 \mathrm{~W}$ tungsten bulb. At intervals, samples ( $0.5 \mathrm{ml})$ were taken and added to $5 \mathrm{ml}$ distilled water and the algae were immediately collected on $1 \cdot 2 \mu \mathrm{m}$ pore size Sartorius membrane filters. After washing with distilled water $(3 \times 20 \mathrm{ml})$ the filters were mounted on planchettes and dried; radioactivity was measured in a Nuclear Chicago gas flow counter. All counts were normalized with respect to the chlorophyll content of the cells.

Ribulosebisphosphate carboxylase [3-phospho-D-glycerate carboxy-lyase (dimerizing), EC 4. I . I . 39]. The reaction mixture contained $(\mu \mathrm{mol})$ : Tris $\mathrm{pH} 7 \cdot 8,100 ; \mathrm{MgCl}_{2}, 5 ;$ EDTA, $0.03 ; \mathrm{NaHCO}_{3}(\mathrm{I} \cdot 0 \mu \mathrm{Ci}), 10$; D-ribulose 1,5-bisphosphate, 0.25 ; and cell extract; total volume, $0.5 \mathrm{ml}$. The reaction was terminated by the addition of $0.5 \mathrm{ml} 2 \mathrm{M}-\mathrm{HCl}$ and the precipitated protein was removed by centrifugation. Supernatant $(0 . \mathrm{I} \mathrm{ml})$ was dispersed in $10 \mathrm{ml}$ Aquasol (New England Nuclear) and the radioactivity was determined using a Beckman LS 200 scintillation counter.

Phosphoribulokinase [ATP:D-ribulose-5-phosphate I-phosphotransferase, EC 2.7.I. I9]. The assay mixture and procedure were as for ribulosebisphosphate carboxylase, except that ribulose 5-phosphate replaced ribulose 1,5-bisphosphate and ATP $(2.5 \mu \mathrm{mol})$ was included. The reaction was started by the addition of ribulose 5-phosphate.

\section{RESULTS}

Under the experimental conditions described, the removal of ammonia from a culture of Anabaena cylindrica caused the differentiation of a proportion of the vegetative cell population. Proheterocysts, recognizable by their larger, rounded shape and less-granular cytoplasm, reached a maximum frequency after $\mathrm{I} 2 \mathrm{~h}$, and these differentiated into mature heterocysts with distinct polar bodies in a rounded cell with a thickened wall and lessgranular cytoplasm (Fig. I). The mature heterocyst frequency reached a maximum around 27 to $33 \mathrm{~h}$ after initiation of the culture. Although $A$. cylindrica is an obligate phototroph, development of proheterocysts and heterocysts proceeded normally when the culture was incubated in the dark, provided that it had been illuminated for $7 \mathrm{~h}$ immediately after the deprivation of ammonia (Fig. 2). This observation permitted a new means of examining the heterocyst development process. Samples of a culture of $A$. cylindrica in which heterocyst development had been initiated were switched from light to dark at different times after initiation and the heterocyst frequency was counted $24 \mathrm{~h}$ after initiation (Fig. 3). Similar results were obtained when $80 \mu \mathrm{M}$-DCMU was added to samples of the culture, kept under continuous illumination, at different times after initiation of heterocyst development (Fig. 3). A period of illumination of 5 to $8 \mathrm{~h}$ before transfer to the dark was sufficient to 


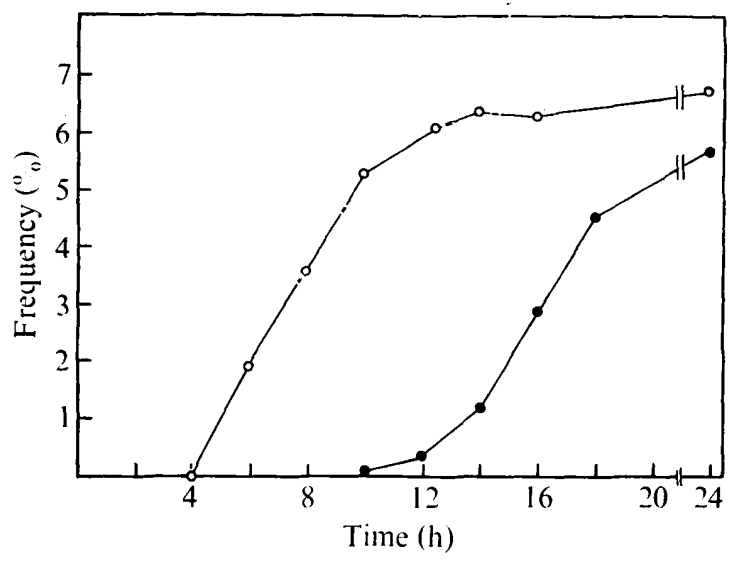

Fig. I. Heterocyst development under the standard conditions: $\bigcirc$, total heterocysts; , mature heterocysts.

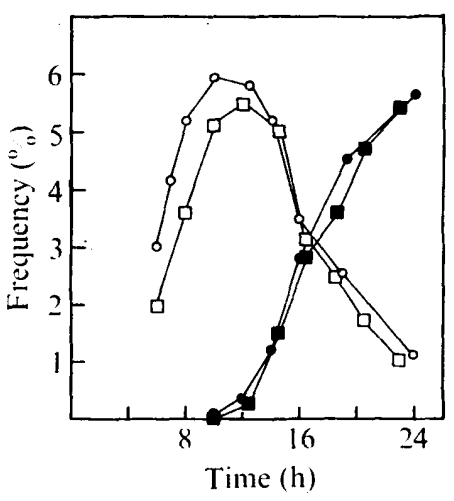

Fig. 2

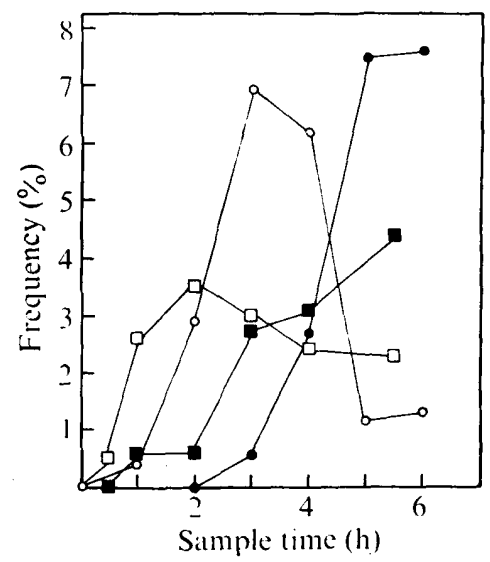

Fig. 3

Fig. 2. Heterocyst development in a culture illuminated for an initial period of $7 \mathrm{~h}$ followed by incubation in the dark, and in a culture illuminated continuously throughout the experiment. Light-dark experiment: $\bigcirc$, proheterocysts; $\bigcirc$, mature heterocysts. Continuous light control: $\square$, proheterocysts; $\mathbf{\square}$, mature heterocysts.

Fig. 3. Differentiated cell frequency in culture samples transferred from normal illumination to the dark, or treated with DCMU in the light, at the times indicated. Frequencies were measured $24 \mathrm{~h}$ after initiation. Light-dark experiment: $\bigcirc$, proheterocysts; $\bigcirc$, mature heterocysts. DCMU treatment: $\square$, proheterocysts; $\boldsymbol{\square}$, mature heterocysts.

allow a culture containing few morphologically distinct cells to develop a full heterocyst complement over the succeeding 16 to $19 \mathrm{~h}$ dark incubation, when compared with a typical continuous light control (cf. Fig. I). These experiments suggested that some cells were starting differentiation after transfer to minimal medium and required $3.5^{5}$ to $5^{\circ} \mathrm{h}$ development before they were morphologically recognizable. This differentiation process was only subject to inhibition by ammonia and inhibitors of RNA synthesis during the period $\mathrm{I} \cdot \mathrm{O}$ to $\mathrm{I} \cdot 5 \mathrm{~h}$ after initiation. The frequency of total heterocysts (i.e. proheterocysts and mature heterocysts), $24 \mathrm{~h}$ after initiation, in samples transferred to dark, dark plus ammonia or dark plus fluorouracil after various periods of normal incubation is shown in Fig. 4. The majority of cells that were to become heterocysts had started differentiation some 8 to io $\mathrm{h}$ after 


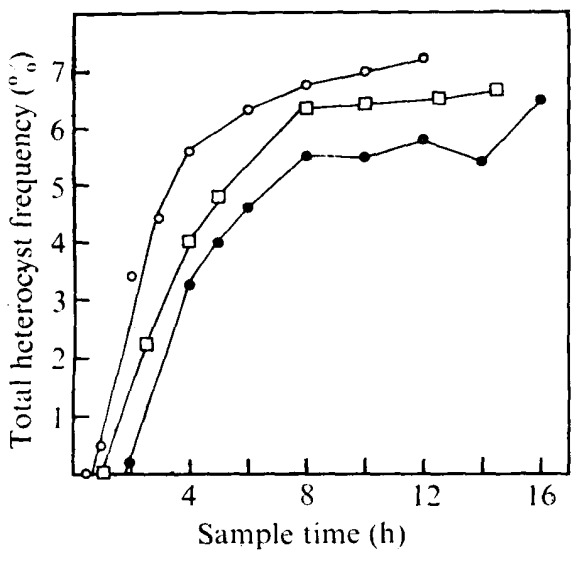

Fig. 4

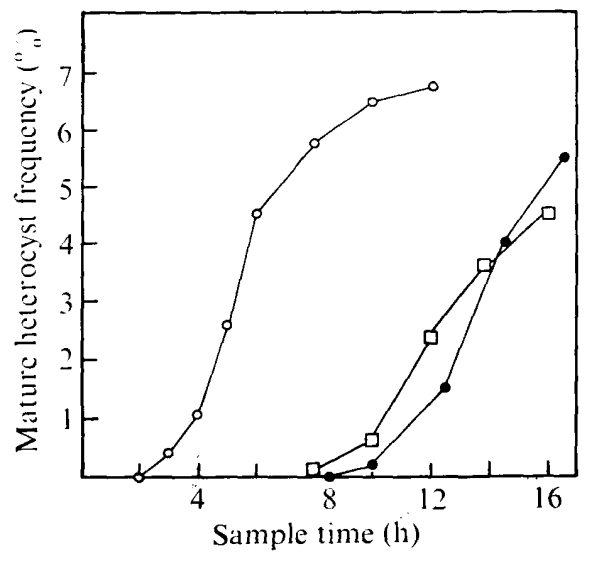

Fig. 5

Fig. 4. Frequency of total heterocysts, measured $24 \mathrm{~h}$ after initiation, in culture samples transferred at the times indicated from normal illumination to the dark $(\bigcirc)$, dark plus $2 \mathrm{~mm}$-ammonium $(\odot)$ or dark plus fluorouracil ( $\square$ ).

Fig. 5. Frequency of mature heterocysts only, measured $24 \mathrm{~h}$ after initiation, in culture samples transferred at the times indicated from normal illumination to the dark $(O)$, dark plus $2 \mathrm{~mm}$ ammonium (O) or dark plus fluorouracil ( $\square$ ).

transfer into ammonia-free media. The final maturation of proheterocysts to become heterocysts could be prevented by adding ammonia and inhibitors of RNA synthesis at times up to $4 \mathrm{~h}$ prior to the detection of mature heterocysts in the continuous light control cultures (Fig. 5).

Carbonyl cyanide p-trifluoromethoxyphenylhydrazone is an inhibitor of oxidative phosphorylation, and when added to a differentiating culture in the dark (after the necessary period of illumination) all development ceased. This suggests that reserve materials were mobilized and de novo synthesis was dependent on the formation of ATP by respiration. Bromodeoxyuridine and bromouracil, inhibitors of DNA synthesis, had no effect on development when compared with the dark controls, suggesting that once any stage of differentiation was initiated, DNA synthesis was either not crucial to the process or it had already been interrupted by dark incubation.

The apparent resistance of development to the presence of DCMU and a partial independence of light prompted an investigation of carbon fixation. This began to decline approximately $\mathrm{I} h$ after transfer to minimal medium and reached levels of about $10 \%$ of the original by 10 to $12 \mathrm{~h}$ with a little increase in activity over the next $16 \mathrm{~h}$, as mature heterocysts became obvious in the culture. Ribulosebisphosphate carboxylase activity declined to $40 \%$ of original by $5 \mathrm{~h}$ and remained at that level for the duration of the experiment, whereas phosphoribulokinase activity was at a minimum level of $20 \%$ activity about $4 \mathrm{~h}$ after resuspension in ammonia-free medium but increased to $50 \%$ by $20 \mathrm{~h}$ (Fig. 6).

\section{DISCUSSION}

Heterocyst development as discussed in this paper is shown diagrammatically in Fig. 7 . After a short obligatory light period the differentiation of vegetative cells to form heterocysts and the associated establishment of a pattern of morphogenesis proceeds in the dark. Since $A$. cylindrica is an obligate phototroph, differentiation must be effected at the expense of endogenous reserves. The breakdown of reserve molecules during heterocyst formation has been noted (Talpasayi \& Kale, 1967; Kulasooriya, Lang \& Fay, 1972) and it seems that 


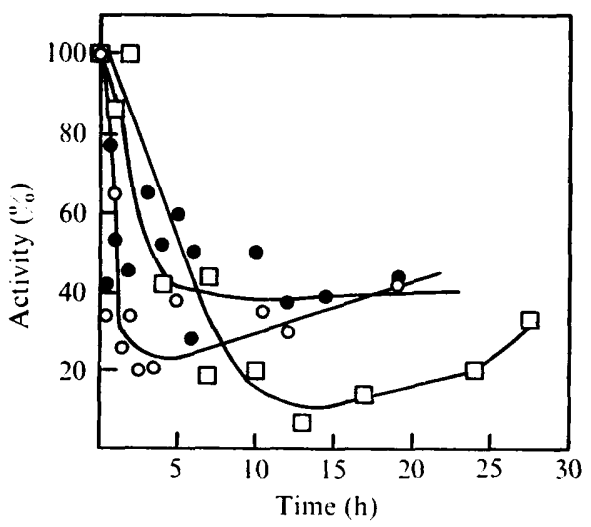

Fig. 6. Variation in ribulosebisphosphate carboxylase $(O)$, phosphoribulokinase $(O)$ and $\mathrm{H}^{14} \mathrm{CO}_{3}{ }^{-}$incorporation ( $\square$ ) during heterocyst development.

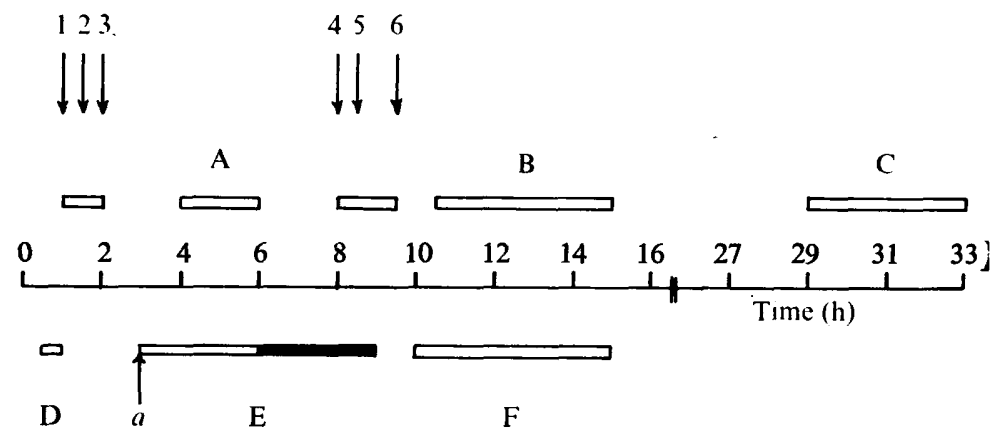

Fig. 7. A schematic plan of heterocyst formation. Proheterocyst commitment times as measured by fluorouracil (I), proflavin (2), rifampicin or ammonium (3). Heterocyst commitment time as measured by ammonium (4), rifampicin or proflavin (5), fluorouracil (6). The initial detection of proheterocysts is indicated by $\mathbf{A}$ and of mature heterocysts by $\mathbf{B}$. Maximum heterocyst frequency occurs at $\mathrm{C}$. The minimum light requirement for proheterocyst formation is indicated by $\mathrm{D}$. The light requirement for heterocyst formation is indicated by $\mathrm{E}: a$ is the minimum light requirement and the black portion is the light required to achieve the maximum number of heterocysts. $\mathrm{F}$ indicates the time of the minimum $\mathrm{CO}_{2}$-fixing activity of the filament.

A. cylindrica adopts a transitory heterotrophic mode of metabolism whilst [adapting to nitrogen starvation. Obviously no net increase in cell mass of a filament is possible during this process and this behaviour recalls that in other examples of microbial development which proceed in the absence of net protein, RNA or cell mass synthesis (see Newell, 197I). The manipulation of the initial illumination period allows the proportion of vegetative cells that become heterocysts to be altered. The minimum period $(0.5 \mathrm{~h})$ permits only proheterocyst development and $3 \mathrm{~h}$ was necessary for any subsequent mature heterocyst formation. A longer period of initial illumination ( 7 to $8 \mathrm{~h}$ ) was needed for the complete pattern of morphogenesis (i.e. identical to that in the continuously illuminated control) to be developed. When a filament of $A$. cylindrica is deprived of fixed nitrogen, metabolic changes commence in all the vegetative cells; some (related to $\mathrm{CO}_{2}$ fixation) are described here and others will form the basis of another paper. We suggest that these metabolic changes form the trigger for development and that the possibility of response to this trigger depends on the stage of the cell division cycle. Thus the shortest period of post nitrogen-deprivation illumination that allows any mature heterocyst formation (i.e. $3 \mathrm{~h}$ ) causes only a small proportion of cells to commit to complete development. Longer periods (up to $9 \mathrm{~h}$ ) allow 
incremental numbers of cells (in the absence of nitrogen) to achieve maturity. The initial linearity of proheterocyst formation suggests that a constant proportion of cells are liable to differentiation as a function of time. This argues that the cell population is heterogeneous in its susceptibility to differentiation, a conclusion reached from quite different evidence by Wilcox et al. (1973). Eventually the total number of cells differentiating is limited, as regularity is imposed on the filaments due to the establishment of inhibitory zones associated with developing cells (Fogg, I949; Wilcox, 1970).

Previous work, under continuous illumination, has shown commitment times of $2.3 \mathrm{~h}$ for proheterocyst and $5 \mathrm{~h}$ for mature heterocyst development (Bradley \& Carr, 1976). Figure 3 shows that the commitment time for proheterocyst formation depends on the means used to inhibit differentiation. Thus 0.5 to $\mathrm{I} \cdot 0 \mathrm{~h}$ is the minimum period of illumination necessary to commit a proportion of vegetative cells to proheterocyst formation. In those cells already committed by light, differentiation is prevented by RNA synthesis inhibition over a period of $\mathrm{I}$ to $2 \mathrm{~h}$, and by the readdition of ammonia up to $2 \mathrm{~h}$, the latter being close to the previously measured value of $2 \cdot 3 \mathrm{~h}$. The light commitment time for mature heterocyst formation is $3 \mathrm{~h}$, but this process is sensitive to inhibition for the next $5 \mathrm{~h}$ (Fig. 5).

These results indicate a series of development stages. They exclude the possibility of the initial formation of a message which codes for the entire developmental programme and favour the concept of a series of sequential messages that direct a vegetative cell to heterocyst formation.

A system in which small populations of the total vegetative filament respond on a sequential time basis to developmental triggers and in which each individual cell has multi-stages of commitment maximizes the flexibility of the total filament response. Thus slight environmental fluctuations would produce a degree of response without mobilizing the entire population and without the complete differentiation of any individual cell unless such environmental fluctuation became pronounced and stabilized.

Singh \& Kumar (197I) reported that DCMU inhibited heterocyst formation in A. doliolum when added to the cultures at the time of resuspension in nitrate-free medium. However, in $A$. cylindrica we observed that this is only true for the first $0.5 \mathrm{~h}$ on minimal medium and that if DCMU is added after increasing periods of illumination, proheterocysts and heterocysts are formed, the numbers being determined by the period of illumination prior to the addition of DCMU. These experiments suggest that the development process depends on an obligatory post-induction phase and a light-independent phase, correlating strongly with the observed dramatic decline in carbon dioxide fixation. This latter effect may be due to the decreased activity of ribulosebisphosphate carboxylase and phosphoribulokinase together with a decline in the formation of the substrates of these enzymes as evidenced by the change in kinetics of glucose-6-phosphate dehydrogenase during differentiation (unpublished).

We are indebted to the Science Research Council for financial support.

\section{REFERENCES}

Allen, M. B. \& ARnon, D. I. (1955). Studies on nitrogen-fixing blue-green algae. I. Growth and nitrogen fixation by Anabaena cylindrica. Plant Physiology 30, 366-372.

Bradley, S. \& CARR, N. G. (I976). Heterocyst and nitrogenase development in Anabaena cylindrica. Journal of General Microbiology 96, I 75-184.

Carr, N. G. \& Bradley, S. (1973). Aspects of development in blue-green algae. Symposia of the Society for General Microbiology 23, 16 I-I 88 .

FOGG, G. E. (1949). Growth and heterocyst produc- tion in Anabaena cylindrica in relation to carbon and nitrogen metabolism. Annals of Botany, N.S. 13, 24I-259.

Kulasooriya, S. A., Lang, N. J. \& Fay, P. (1972). The heterocysts of blue-green algae. III. Differentiation and nitrogenase activity. Proceedings of the Royal Society Br8r, 199-200.

NEWELL, P. (197I). The development of the cellular slime mould Dictyostelium discoideum: a model system for the study of cellular differentiation. Essays in Biochemistry, 7, 87-1 26. 
Singh, H. N. \& Kumar, H. D. (197I). Physiology of heterocyst production in the blue-green alga Anabaena doliolum. 1. Nitrate and light controls. Zeitschrift für allgemeine Mikrobiologie $\mathbf{I}$, 615-622.

Talpasayi, G. R. S. \& Kale, K. S. (I967). Induction of heterocysts in the blue-green alga Anabaena ambigua. Current Science 36, 218-219.

WILCOX, M. (1970). One-dimensional patterns found in blue-green algae. Nature, London 228, 686687.

Wilcox, M., Mitchison, G. J. \& SMith, R. J.
(1973). Pattern formation in the blue-green alga Anabaena. Journal of Cell Science 12, 707-723.

Wilcox, M., Mrtchison, G. J. \& Smith, R. J. (1975). Spatial control of differentiation in the blue-green alga Anabaena. In Microbiology1975, pp. 453-463. Edited by D. Schlessinger. Washington: American Society for Microbiology.

WoLk, C.P. (1975). Differentiation and pattern formation in filamentous blue-green algae. In Spores VI, pp. 85-96. Edited by P. Gerhardt, H. L. Sadoff and R. N. Costilow. Washington: American Society for Microbiology. 